\title{
Simplification and Evaluation of a Gold-deposited SPR Optical Fiber Sensor
}

\author{
Masaru Mitsushio ${ }^{\dagger}$ and Morihide Higo \\ Department of Applied Chemistry and Chemical Engineering, Faculty of Engineering, \\ Kagoshima University, 1-21-40, Korimoto, Kagoshima 890-0065, Japan
}

\begin{abstract}
The structure of the sensing element of a gold-deposited optical fiber sensor was simplified and quantitative analyses of various alcohols with the sensor showed improvement of the performance. The sensor uses surface plasmon resonance (SPR) at the interface of a sample solution and a thin $(10-70 \mathrm{~nm})$ gold film deposited on half of the exposed core of the optical fiber. The sensor with a film thickness of $45 \mathrm{~nm}$ can detect a small change of $5.6 \times 10^{-5}$ refractive index (RI) units in the refractivity. The response time is less than $0.5 \mathrm{~min}$ and the relative standard deviation for measurements is less than or equal to $1 \%$. A straight line with a correlation coefficient of 0.9995 was obtained below $10 \%, v / v$ in the calibration curve for methanol solutions of benzyl alcohol. The minimum of the response curve due to the maximum excitation of SPR in the refractivity range from 1.33 to 1.44 RI units shifts to a lower refractivity as the film becomes thicker. The response curves of the sensors were calculated from SPR theoretical equations while considering of the distribution in the thickness of the deposited gold films. The improvement in the performance of the sensor is discussed.
\end{abstract}

(Received November 20, 2003; Accepted February 25, 2004)

\section{Introduction}

New sensor systems using surface plasmon resonance (SPR) have been developed for measuring the refractive index (RI) of an analyte. ${ }^{1,2}$ The systems use an optical phenomenon in which incident light excites a charge-density wave at the interface between a metal and a dielectric., ${ }^{1,2}$ An SPR sensor allows the realization of quick determination of the RI of a sample with high accuracy. However, the usual SPR sensor systems utilize bulk optical configurations that are limited by the use of a coupling prism. Furthermore, since the SPR system requires a spectrometer or a rotation stage, the resulting systems are relatively large and expensive, are inapplicable for remote sensing applications. ${ }^{3}$

Optical fiber sensors based on the SPR phenomenon have been developed. ${ }^{3-29}$ These systems replace a coupling prism with an optical fiber, and the SPR phenomenon is applicable to analyses of liquid or gas samples. The systems have a sensing element of a deposited metal film on the core of an optical fiber and must scan the wavelength ${ }^{3,4}$ or change the angle of incident light. $^{5-15}$ Another type of the sensor based on SPR in a thin deposited metal film on the core of an optical fiber implanted in a silica block and polished has been reported. ${ }^{16-23}$ A gold island SPR sensor has also been investigated. ${ }^{24-29}$ Most theoretical analyses for the optical fiber sensors using SPR are based on the traditional Kretschmann configuration and the response curves have been calculated. ${ }^{3,6,12,14,16-23,30-34}$ However, these analyses are made for the sensors in a restricted range of the refractivity (less than 1.45 RI units). Thus, a theoretical investigation of the response of the gold-deposited optical fiber sensor over a wider range of refractivity is necessary to understand the mechanism

$\doteqdot$ To whom correspondence should be addressed.

E-mail: m-mitsus@apc.kagoshima-u.ac.jp of the response.

An optical fiber sensor system based on SPR without scanning the wavelength or changing the angle of incident light is desired for remote sensing, continuous analysis, and in situ monitoring using a small and inexpensive sensing element. We have already developed a small and simple gold-deposited optical fiber sensor system without scanning the wavelength or changing the angle of incident light. ${ }^{35-40}$ The sensing element has a thin $(30-60 \mathrm{~nm})$ gold film deposited all around the bare core of an optical fiber and a sample solution flows around it. When light with an intensity distribution is introduced into the optical fiber of the sensor with a focusing lens, the SPR occurs at the interface between the gold film and the sample solution. A part of the incident light disappears by the SPR and the intensity of the transmitted light varies depending on the refractivity of the sample solution..$^{35-40}$ We have performed the analyses of various alcohol solutions ${ }^{35-40}$ and some esters in ethanol $^{36}$ and have demonstrated the usefulness of this sensor system. Theoretical analyses for the responses of these sensors over a wide range of refractivity $(1.33-1.54$ RI units $)$ with traditional SPR equations and the Fresnel equation have also been carried out and a good agreement was obtained between the results. ${ }^{39}$ Though the core of the gold-deposited optical fiber sensors is completely covered with thin gold films, the response curve has a sharp minimum at 1.462 RI units due to the leakage of the light through defects in the thin deposited gold films to the sample solution with the same refractivity as that of the core. ${ }^{37,39,40}$ The surface morphology of the deposited gold films on glass observed by atomic force microscopy (AFM) and a variation in resistance of the films with various thicknesses support the above findings. ${ }^{37,39,40}$

In the present study, the structure of the sensing element of the gold-deposited optical fiber sensor has been simplified and the performance has been evaluated for quantitative analyses of various alcohols. A gold film with thicknesses of $10-80 \mathrm{~nm}$ 


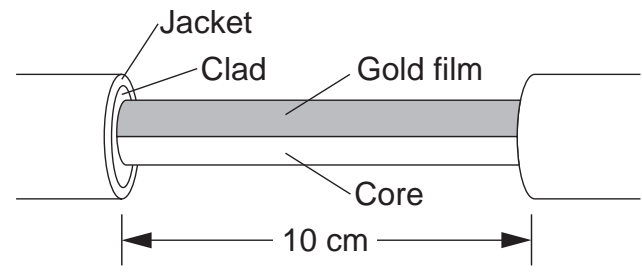

Fig. 1 Schematic representation for the simplified sensing element of the gold-deposited optical fiber. A thin $(45 \mathrm{~nm})$ gold film was deposited on half of the core of the optical fiber as shown in the figure.

was deposited onto half of the bare core of the optical fiber. The response curves of these simplified sensing elements of the gold-deposited optical fibers were investigated in the refractivity range from 1.33 to 1.54 RI units. Theoretical calculations with a consideration of the thickness distribution in the deposited gold films were also carried out and compared with the experimental results.

\section{Experimental}

\section{Construction of the sensing element}

The procedure and materials for preparing the sensing element were the same, ${ }^{35-40}$ except for deposition of the gold film. The diameters of the core, clad, and jacket of a plastic cladding stepindex multi-mode optical fiber (Showa Electric Wire \& Cable NJ-PF200/300) were 200, 300, $900 \mu \mathrm{m}$, respectively. The clad and jacket $(10 \mathrm{~cm}$ long) were removed by immersing the optical fiber in concentrated sulfuric acid. The gold film was deposited onto half of the exposed bare core at a pressure of about $6 \times 10^{-6}$ Torr $(1$ Torr $=133.322 \mathrm{~Pa})$ and at a room temperature. The deposition rate was from 0.4 to $0.8 \mathrm{~nm} / \mathrm{s}$. A schematic representation for the deposited gold film and the sensing element of the gold-deposited optical fiber is shown in Fig. 1. Since the gold film was deposited on the half of the columnar core of the optical fiber, it had a distribution in the thickness. However, the maximum value in the distribution represented the thickness of the gold film for a convenience. The simplified sensing element of the gold-deposited optical fiber and Teflon tubes for a sample inlet and outlet were fixed in a glass tube (12 $\mathrm{cm}$ long and $0.3 \mathrm{~cm}$ in diameter) with resin to form the sensor cell. Sample solutions maintained at $25^{\circ} \mathrm{C}$ flowed at a rate of $0.098 \mathrm{ml} / \mathrm{s}$ through the sensor cell with a micro-tube pump.

\section{Apparatus}

The details of the sensor system were already reported. ${ }^{39,40}$ The light of a He-Ne laser (Melles Griot V05LHR151) with a stabilized power supply was focused normally on the edge of the optical fiber and introduced into the core with a simple spherical lens (50 $\mathrm{mm}$ focal length). The transmitted light through the sensor was measured with an optical multimeter (ILX Lightwave OMM-6810B) equipped with a Si detector (ILX Lightwave VOMM-6722B). The light intensity was converted to digital data with a digital multimeter (YOKOGAWA 755501-1) as an A/D converter, and monitored with a computer (NEC PC-9821 Xs). Refractive indices of solutions were measured at $25^{\circ} \mathrm{C}$ with an Abbe refractometer (ATAGO DR-A1).

\section{Reagents}

All alcohols were obtained from Wako Pure Chemical

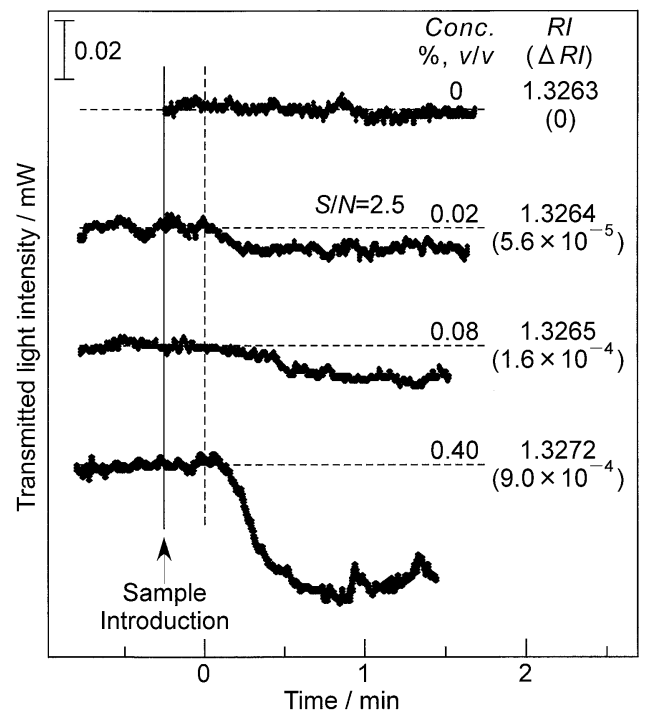

Fig. 2 Responses of the simplified gold-deposited optical fiber sensor with a film thickness of $45 \mathrm{~nm}$ to methanol solutions of benzyl alcohol with various concentrations. The concentration is a volume $\%$ $(\%, \mathrm{v} / \mathrm{v})$. The refractive index $(\mathrm{RI})$ and the change $(\Delta \mathrm{RI})$ of the solution are also shown.

Industries and used without further purification.

\section{Results and Discussion}

\section{Properties of the sensor}

The responses of a simplified gold-deposited optical fiber sensor with the film thickness of $45 \mathrm{~nm}$ to methanol solutions of benzyl alcohol with various concentrations are shown in Fig. 2. The concentration of the solution is a volume $\%(\%, v / v)$. The refractivities and their changes of the sample solutions are also shown in the figure. The Abbe refractometer showed no change in the refractivities of the concentrations of 0.02 and $0.08 \%$. However, since the refractivities of the solutions were proportional to the concentrations in the range from 0 to $10 \%$ with a correlation coefficient of 0.9996 , the values of the refractivities of 0.02 and $0.08 \%$ were calculated from those of the refractivities of 2.00 and $8.00 \%$, respectively. When sample solutions of more than or equal to $0.02 \%$ were introduced into the sensor cell, the transmitted light intensity through the core of the gold-deposited optical fiber decreased after $0.25 \mathrm{~min}$ from the sample introduction and became a constant value within $0.5 \mathrm{~min}$. The delay of $0.25 \mathrm{~min}$ is caused by the sample flow through the inlet of the sensor cell. The response time $(0.5$ $\mathrm{min}$ ) is the time required for a complete exchange of a sample solution in the sensor cell. The detection limit of $0.02 \%$ and the change of $5.6 \times 10^{-5} \mathrm{RI}$ units with a signal-to-noise ratio $(S / N)$ of 2.5 were obtained by the computer analysis. The signal was defined as a difference between the average of transmitted light intensities for $0.5 \mathrm{~min}$ of methanol before the sample introduction and that of transmitted light intensities for $0.5 \mathrm{~min}$ after the light intensity became constant. The noise was twice of the standard deviation of transmitted light intensities for 0.5 min of the sample solution after the response. Our previous gold-deposited optical fiber sensor system without a computer had the detection limit of $0.5 \%$ and the change of $0.0012 \mathrm{RI}$ units for phenethyl alcohol..$^{38}$ The detection limit of $0.05 \%$ and the change of $0.0001 \mathrm{RI}$ units for benzyl alcohol were obtained 


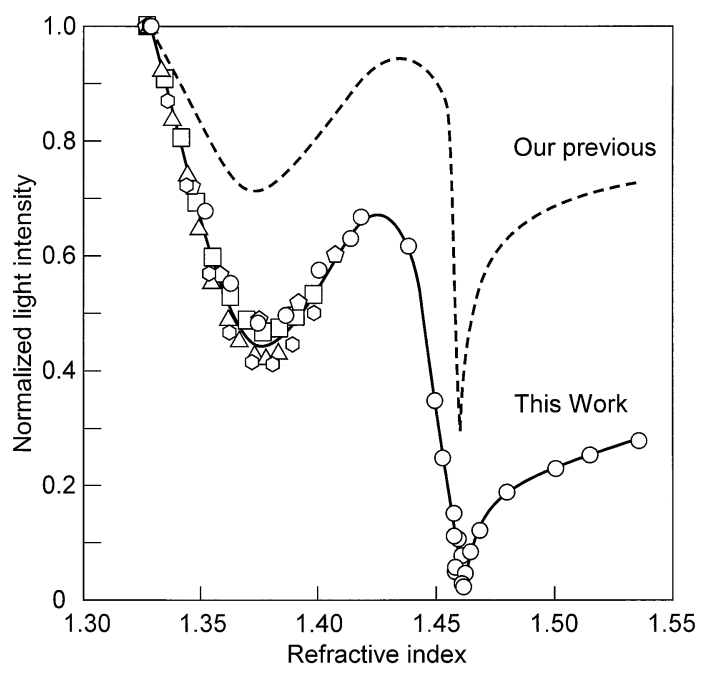

Fig. 3 Response curve of the simplified gold-deposited optical fiber sensor with a film thickness of $45 \mathrm{~nm}$ for methanol solutions of various alcohols. The response curve of our previous gold-deposited optical fiber sensor with the film $(45 \mathrm{~nm})$ deposited all around the core to methanol solutions of various alcohols is also shown. Key: ( $\triangle$ ) 1-propanol; ( $\square$ ) 1-butanol; ( $($ ) 1-pentanol; ( ○) 1-hexanol; (o) benzyl alcohol.

by the computer analysis. ${ }^{40}$ The detection limit of the simplified gold-deposited optical fiber sensor is about twice lower than that of our previous gold-deposited optical fiber sensor. ${ }^{40}$ The reason for the higher sensitivity is discussed below.

The calibration curve of the simplified gold-deposited optical fiber sensor with a film thickness of $45 \mathrm{~nm}$ for methanol solutions of benzyl alcohol had the straight line with a correlation coefficient of 0.9995 in the concentration range below $10 \%$. The relative standard deviations were below $1 \%$ for all of the solutions. We have reported the correlation coefficients of 0.998 and 0.997 for the previous gold-deposited optical fiber sensor in the concentration ranges below 5\% for methanol solutions of phenethyl alcohol ${ }^{38}$ and below $6 \%$ for methanol solutions of benzyl alcohol, ${ }^{40}$ respectively. The simplified gold-deposited optical fiber sensor has the wider dynamic range and the lower detection limit with the higher accuracy than the previous sensor.

The response curve of the simplified gold-deposited optical fiber sensor with a film thickness of $45 \mathrm{~nm}$ to the wide range of refractivities from 1.326 to 1.537 RI units of methanol solutions of 5 alcohols is shown in Fig. 3. The transmitted light intensities for the solutions were measured and normalized by that for the solvent at $1.326 \mathrm{RI}$ units. The response of our previous gold-deposited optical fiber sensor with the film (45 $\mathrm{nm}$ ) deposited all around the core is also shown in the figure by the dashed line for a comparison. The relative standard deviations of the light intensities for all of the solutions of the simplified gold-deposited optical fiber sensor were less than or equal to $1 \%$ by 3 repeated measurements. Both response curves of the gold-deposited optical fiber sensors had the broad and sharp minima at the same refractivities at $1.375 \pm 0.003$ and $1.462 \pm 0.001 \mathrm{RI}$ units, respectively. However, the former broad response due to the SPR of the simplified gold-deposited optical fiber sensor was about twice larger than that of the previous sensor. The maximum near $1.43 \mathrm{RI}$ units of the simplified gold-deposited optical fiber sensor was lower than that of the previous sensor. Since the total reflection at the

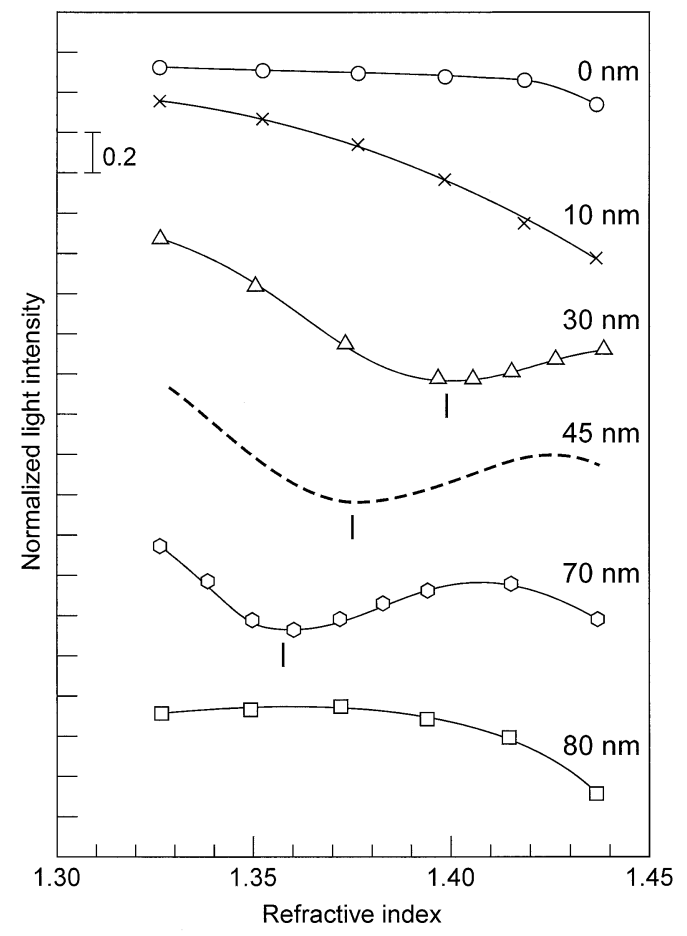

Fig. 4 Response curves of the simplified gold-deposited optical fiber sensors with film thicknesses of 10, 30, 45, 70, and $80 \mathrm{~nm}$ for methanol solutions of benzyl alcohol. The response curve of the bare core optical fiber without a gold film $(0 \mathrm{~nm})$ is also shown.

surface of the exposed core occurs below a refractivity of 1.43 RI units, there was no loss of light in this refractivity range. The minimum at $1.462 \mathrm{RI}$ units is caused by almost complete loss of the light from the half of the exposed core to the sample solution with the same refractivity. This value $(1.462 \pm 0.001)$ of the refractivity at the minimum was that of the core of the present optical fiber and was very close to that of quartz (1.4572 RI units at $632.8 \mathrm{~nm}$ and at a room temperature). The estimated slopes of the response curve were -15.03 and 5.88 for the ranges of $1.33-1.36$ and $1.38-1.42$ RI units, respectively. These slopes have no dimension and represent the sensitivities of the simplified gold-deposited optical fiber sensor to refractivities of methanol solutions of various alcohols. The response curve of the previous gold-deposited optical fiber sensor had the slopes of -8.32 and 4.90 for the same refractivity ranges. ${ }^{39,40}$ Therefore, the simplified sensor had 1.81 and 1.20 times as higher sensitivities as the previous sensor for the ranges of $1.33-1.36$ and $1.38-1.42$ RI units, respectively. The high sensitivity and the good accuracy $(\leq 1 \%)$ of the simplified golddeposited optical fiber sensor caused the lower detection limit of $5.6 \times 10^{-5} \mathrm{RI}$ units and the better correlation coefficient of 0.9995 in the calibration curve. The simplified sensing element of the gold-deposited optical fiber sensor also had more uniform performance that our previous sensing element which was prepared by the deposition of gold films all around the bare core by rotating the optical fiber every $90^{\circ} .{ }^{35-40}$

The typical response curves of the simplified gold-deposited optical fiber sensors with thicknesses of 10, 30, 45, 70, and 80 $\mathrm{nm}$ to the range of refractivities from 1.326 to $1.437 \mathrm{RI}$ units of methanol solutions of benzyl alcohol are shown in Fig. 4. The response curve of a bare core optical fiber without a gold film (0 $\mathrm{nm})$ is also shown. The transmitted light intensities of these sensors were also normalized by that for the solvent. The response curve of the bare core optical fiber showed total 
reflection in the refractivity range below 1.43 RI units. The minimum of the response curve due to the SPR phenomenon of the sensor shifted to a lower refractivity as the film became thicker and no minimum was located in the response curve of the film with a thickness of $80 \mathrm{~nm}$. The refractivities of the minima were $1.399 \pm 0.003,1.375 \pm 0.003$, and $1.357 \pm 0.003$ RI units for thicknesses of 30,45 , and $70 \mathrm{~nm}$, respectively. This is the same tendency as the peak shift of the previous golddeposited optical fiber sensor, ${ }^{38-40}$ and thus, the sensitivity and response curve of the simplified gold-deposited optical fiber sensor can also be controlled by the film thickness.

Gagnaire et al..$^{712}$ and Jaffrezic-Renault et al. ${ }^{13}$ have constructed a gold-deposited multi-mode optical fiber sensor system with changing the angle of incident light. A golddeposited optical fiber sensor with a thickness of $50 \mathrm{~nm}$ and a sensing length of $15 \mathrm{~mm}$ had the detection limit of about $2 \times$ $10^{-4} \mathrm{RI}$ units in the ranges from 1.33 to 1.35 and from 1.36 to 1.39 RI units at the incident angles of $6^{\circ}$ and $8^{\circ}$, respectively. ${ }^{7}$ Since the reflecting point at the interface of the core and the metal shifts with changing the incident angle, the core must be covered with a gold film with a uniform thickness. Alonso et $a l .{ }^{16}$ and Homola et al. ${ }^{18-23}$ have developed the sensor with a thin deposited gold film on the core of a side polished single-mode optical fiber implanted in a silica block. The incident light was guided into the sensor through a polarization controller and was detected at the end of the optical fiber. ${ }^{17-21}$ These golddeposited optical fiber sensors with film thicknesses of 25 to 45 $\mathrm{nm}$ had the resolution of $2 \times 10^{-5}$ over the range from 1.38 to 1.43 RI units. ${ }^{17-21}$ Though this sensor had a high resolution probably due to the effective SPR at the single-mode optical fiber with an optimum bend, the fabrication of the sensing element and the optics of the system were complicated. Meriaudeau et al..$^{24-29}$ have fabricated the optical fiber sensor using a gold island film configuration with sweeping the wavelength. The thin $(4 \mathrm{~nm})$ gold layer was deposited around the core $(2.5 \mathrm{~cm}$ long and the diameter of $1 \mathrm{~mm})$ of an optical fiber and the layer was annealed to form uniform isolated spheroids. The surface of the thin gold layer was covered with $\mathrm{MgF}_{2}$ to prevent the leakage of light. Though the refractivity range was broad between 1 to $1.7 \mathrm{RI}$ units, the sensor had poor sensitivity or resolution of the order of a few tenths of RI units probably because the gold layer was too thin for the interaction of a surface plasmon wave and an evanescent wave.

\section{Theoretical analysis and numerical calculation of the response} curve

The principle for the metal-deposited optical fiber sensors using SPR is based on the Kretschmann configuration; models of the response have been proposed. ${ }^{3,6,12,14,16-23,30-34} \mathrm{Xu}$ et al. $^{33}$ assumed that the theoretical models of SPR for bulk optics are satisfied by meridional rays in optical fibers and calculated the optical power transmittance of a gold-deposited multi-mode optical fiber sensor as a function of a wavelength. We have also considered the meridional rays and assumed single reflection without a range of incident angles in a multi-mode optical fiber for simplicity. ${ }^{39}$ The model for the response of the previous gold-deposited optical fiber sensor, the theoretical equations, and the procedures for the numerical calculations have been described in detail before. ${ }^{39}$ A brief summary follows.

The propagation constant of the evanescent wave $\left(k_{\mathrm{ev}}\right)$ is related to the SPR propagation constants of the dispersion relation of SPR $\left(k_{0}\right)$ and the perturbation due to the finite physical volume of the metal film $\left(k_{\mathrm{r}}\right)$ in the resonance condition. ${ }^{33,39}$ An SPR angle $(\theta)$ can be obtained from the equation $k_{\mathrm{ev}}=k_{0}+k_{\mathrm{r}}$, a function of the wavelength of the

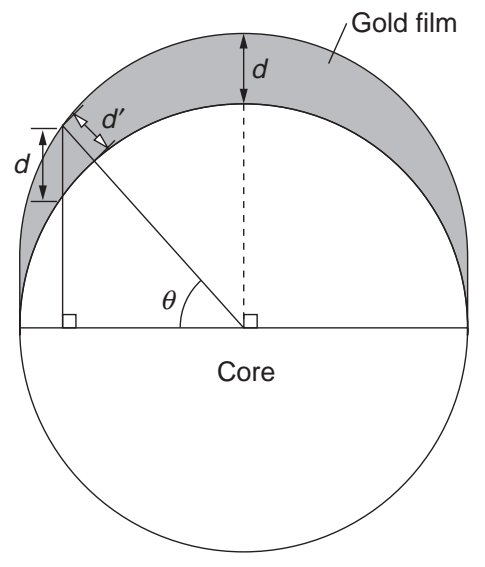

Fig. 5 Schematic cross section for the sensing element of the simplified gold-deposited optical fiber sensor with a thickness of $d$. The deposited gold film on half of the core has a distribution in the thickness.

incident light $(\lambda)$, film thickness $(d)$, real part of the dielectric constant of gold $\left(\varepsilon_{\mathrm{m}}\right)$, RI of the core $\left(n_{\mathrm{c}}\right)$, and the refractivity of a sample $\left(n_{\mathrm{s}}\right)$. The values of $\lambda, \varepsilon_{\mathrm{m}}$, and $n_{\mathrm{c}}$ used for the calculations were $632.8 \mathrm{~nm},-11.836107,{ }^{31}$ and $1.462,{ }^{39}$ respectively. The intensity distribution for an incident angle of the collimated laser light was calculated. ${ }^{39}$ The reflectivity at the interface between the core and the sample was assumed to be unity in the refractivity range below 1.462 RI units where the total reflection occurs. ${ }^{39}$ The full width at half maximum (FWHM) of a peak in the SPR reflection spectrum of a gold film was estimated to be $2^{\circ}$ and the reflectivity in the angle range $\left(\theta \pm 1^{\circ}\right)$ of the SPR was assumed to become $0 .{ }^{39}$ The theoretical response curve was obtained by subtracting the light intensity absorbed due to the SPR between the angle range from the total intensity.

We calculated the response curves of the previous golddeposited optical fiber sensors using a planar waveguide and a uniform thickness of the gold film as described above. ${ }^{39}$ However, the sensing element of the simplified gold-deposited optical fiber sensor has a columnar structure and a distribution in the thickness of the gold film. Figure 5 shows a schematic cross section for the sensing element of the simplified sensor with a film thickness of $d$. The gold film has the distribution in the thickness from 0 to $d$ and thus, the theoretical calculations for the response curve of the sensing element need to consider this thickness distribution. The thickness of $d^{\prime}$ for every $0.45^{\circ}$ at the central angle from $0^{\circ}$ to $180^{\circ}$ was calculated from the geometrical configuration. Theoretical response curves were obtained from the numerical calculations for each film thickness of $d^{\prime}$. The experimental response curve for a thickness of $30 \mathrm{~nm}$ had a minimum at 1.399 RI units, whereas the theoretical curves for thicknesses less than $30 \mathrm{~nm}$ had minima above the refractivity of the core (1.462 RI units). However, no total reflection occured at these refractivities, and film thicknesses below $30 \mathrm{~nm}$ did not satisfy the actual SPR conditions. Therefore, the theoretical response curve for a thickness of $d$ was made from the average of these calculations for $d^{\prime}$ more than or equal to $30 \mathrm{~nm}$. We also assumed that all films with these thicknesses have an equal efficiency for SPR. The numerical calculations were made for every $1 \times 10^{-3} \mathrm{RI}$ units.

The theoretical response curves for film thicknesses of 45 and $70 \mathrm{~nm}$ in the refractivity range from 1.310 to $1.430 \mathrm{RI}$ units are shown in Fig. 6. The theoretical response curves were 


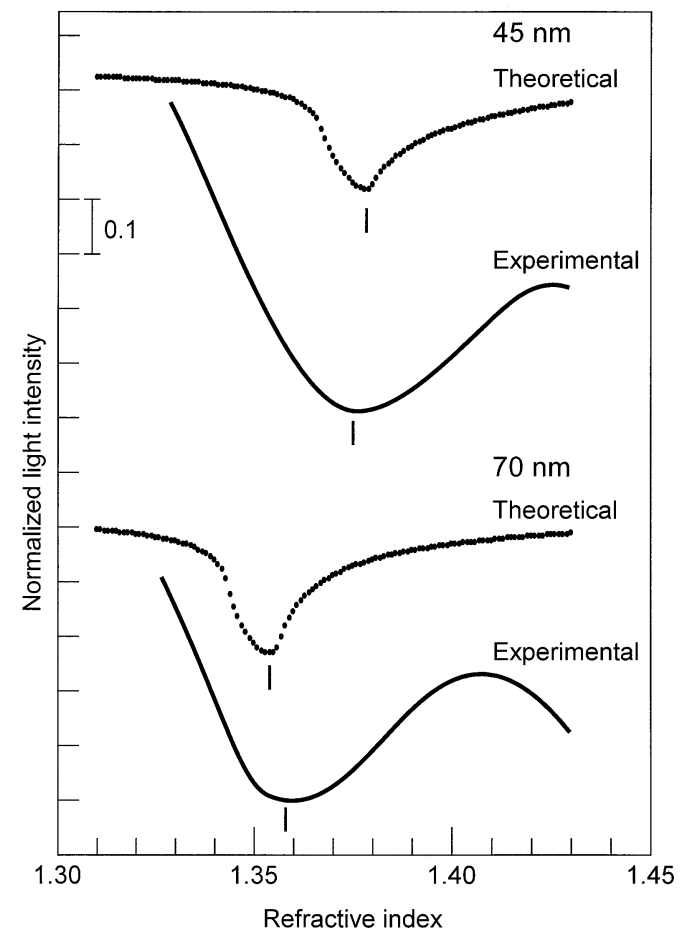

Fig. 6 Response curves of the simplified gold-deposited optical fiber sensors with a thicknesses of 45 and $70 \mathrm{~nm}$ calculated from the SPR theoretical equations. The experimental response curves of the simplified gold-deposited optical fiber sensors with the same film thicknesses are also shown.

normalized by the intensities at the refractivity of $1.326 \mathrm{RI}$ units for the solvent of methanol. The experimental response curves for the corresponding thicknesses of the simplified golddeposited optical fiber sensors are also shown by the solid lines. The refractivities of the minima in the theoretical curves for film thicknesses of 45 and $70 \mathrm{~nm}$ were 1.378 and $1.354 \mathrm{RI}$ units, respectively. For using $n_{\mathrm{c}}=1.4572 \mathrm{RI}$ units for quartz, the refractivities of the minima for thicknesses of 45 and $70 \mathrm{~nm}$ were 1.375 and 1.350 , respectively. Thus, we estimated the uncertainty in the refractivities of the minima in the theoretical curves to be about \pm 0.004 RI units. Different values of $\varepsilon_{\mathrm{m}}$ may also cause the differences in the refractivity of the minimum. The refractivities of the minima in the theoretical response curves for thicknesses of 45 and $70 \mathrm{~nm}$ agreed well with those in the experimental response curves $(1.375 \pm 0.003$ and $1.357 \pm$ 0.003 RI units, respectively).

We have calculated and reported the theoretical response curves of the previous gold-deposited optical fiber sensors. ${ }^{39}$ The calculated response curve had a symmetrical shape centering around the minimum because the film was assumed to have a uniform thickness with no distribution. On the other hand, the theoretical response curve of the simplified golddeposited optical fiber sensor has an asymmetrical shape. This asymmetry results from the contribution of the responses of the thinner films $\left(d^{\prime}\right)$ at higher refractivities than that of the minimum. However, the response of this sensing element has no effect of the thickness distribution for lower refractivity than that of the minimum. The simplified sensing element has advantages of easy fabrication, high sensitivity, and uniform performance. The theoretical curves are sharper than the experimental curves. This is mainly caused by the assumption of the single reflection without a range of incident angles in spite of multi-reflection and the range of incident angles in the multi-mode optical fiber. The intensity distribution of the laser used in the theoretical calculation may be narrower than the actual distribution. The assumption of the single reflection also gives the smaller responses in the theoretical curves.

It becomes clear that the simplified sensing element of the gold-deposited optical fiber sensor has the higher sensitivity and accuracy than the previous sensing element in the refractivity range of $1.33-1.36 \mathrm{RI}$ units. The previous sensing element was prepared by the deposition of gold films on the core by rotating the optical fiber every $90^{\circ}$. Thus, it really had an overlap of the deposited films and a thicker distribution in the thickness. The thicker distribution in the films had influence on the response curve for a lower refractivity than that of the minimum and therefore decreased the sensitivity of the previous sensing element. On the other hand, the simplified sensing element had only the thinner distribution in the film thickness and had no influence on the response curve for a lower refractivity. We conclude that the present sensor utilizes the SPR absorption effectively at the deposited gold film on the core of the optical fiber and that it is an excellent sensor for refractivities.

\section{Conclusions}

The sensing element of the gold-deposited optical fiber sensor system for measuring refractive indices of liquid samples using SPR has been simplified and the capability has been investigated over a wide range of refractive indices of various alcohols. The sensing element is easily prepared by the deposition of the gold film on half of the core of the optical fiber which improved the performance. The core of the sensing element has no necessity to be completely covered with gold films. The sensor system has the simple construction and enables us to perform remote sensing, continuous analysis, and in situ monitoring of liquid samples with the detection limit of $5.6 \times 10^{-5}$ RI units. The response curve of the simplified golddeposited optical fiber sensor with a film thickness of $45 \mathrm{~nm}$ had the broad and sharp minima at $1.375 \pm 0.003$ and $1.462 \pm$ $0.001 \mathrm{RI}$ units, respectively. The minimum at $1.375 \mathrm{RI}$ units caused by the maximum excitation of SPR at the interface between the gold film and the sample solution shifted to a lower refractivity as the film became thicker. Therefore, the properties of the sensor can be controlled by changing the film thickness. The minimum at $1.462 \mathrm{RI}$ units was caused by the leakage of the light from the exposed core to a sample solution. The response curves of the sensors with the thicknesses of 45 and $70 \mathrm{~nm}$ agreed well with those calculated from SPR theoretical equations with a consideration of the thickness distribution in the deposited gold film.

\section{References}

1. J. Homola, S. S. Yee, and G. Gauglitz, Sens. Actuators B, 1999, $54,3$.

2. H. Muguruma, Bunseki, 2003, 38 .

3. R. C. Jorgenson and S. S. Yee, Sens. Actuators B, 1993, 12, 213.

4. R. C. Jorgenson and S. S. Yee, Sens. Acturtors A, 1994, 43, 44.

5. C. Ronot-Trioli, A. Trouillet, C. Veillas, A. El-Shaikh, and H. Gagnaire, Anal. Chim. Acta, 1996, 319, 121.

6. A. Trouillet, C. Ronot-Trioli, C. Veillas, and H. Gagnaire, Pure Appl. Opt., 1996, 5, 227.

7. C. Ronot-Trioli, A. Trouillet, C. Veillas, and H. Gagnaire, 
Sens. Actuators A, 1996, 54, 589.

8. A. Abdelghani, J. M. Chovelon, J. M. Krafft, N. JaffrezicRenault, A. Trouillet, C. Veillas, C. Ronot-Trioli, and H. Gagnaire, Thin Solid Films, 1996, 284/285, 157.

9. A. Abdelghani, C. Veillas, J. M. Chovelon, N. JaffrezicRenault, and H. Gagnaire, Synth. Met., 1997, 90, 193.

10. A. Abdelghani, J. M. Chovelon, N. Jaffrezic-Renault, C. Ronot-Trioli, C. Veillas, and H. Gagnaire, Sens. Actuators $B, \mathbf{1 9 9 7}, 38 / 39,407$.

11. A. Trouillet, C. Veillas, J. P. Goure, and H. Gagnaire, SPIE, 1998, 3483, 109.

12. W. B. Lin, N. Jaffrezic-Renault, A. Gagnaire, and H. Gagnaire, Sens. Actuators, 2000, 84, 198.

13. W. B. Lin, J. M. Chovelon, and N. Jaffrezic-Renault, Appl. Opt., 2000, 39, 3261.

14. W. B. Lin, M. Lacroix, J. M. Chovelon, N. JaffrezicRenault, and H. Gagnaire, Sens. Actuators B, 2001, 75, 203.

15. A. Abdelghani and N. Jaffrezic-Renault, Sens. Actuators B, 2001, 74, 117.

16. R. Alonso, F. Villuendas, J. Tornos, and J. Pelayo, Sens. Actuators A, 1993, 37/38, 187.

17. J. Holola, Sens. Actuators B, 1995, 29, 401.

18. J. Homola and R. Slavík, Electron. Lett., 1996, 32, 480.

19. R. Slavík, J. Homola, and J. Čtyroký, SPIE, 1997, 3105, 325.

20. R. Slavík, J. Homola, and J. Čtyroký, Sens. Actuators B, 1998, $51,311$.

21. R. Slavík, J. Homola, and J. C̆tyroký, Sens. Actuators B, 1999, 54,74

22. R. Slavík, J. Homola, J. C̆tyroký, and E. Brynda, Sens. Actuators B, 2001, 74, 106.

23. R. Slavík, J. Homola, and E. Brynda, Biosens. Bioelectron., 2002, 17, 591.

24. F. Meriaudeau, T. D. Downey, A. Passian, A. G. Wig, S.
Mangeant, P. B. Crilly, and T. L. Ferrell, SPIE, 1998, 3491, 1179.

25. F. Meriaudeau, T. Downey, A. Wig, A. Passian, M. Buncick, and T. L. Ferrell, Sens. Actuators B, 1999, 54, 106.

26. F. Meriaudeau, A. Wig, A. Passian, T. Downey, M Buncick, and T. L. Ferrell, SPIE, 1999, 3860, 214.

27. F. Meriaudeau, A. Wig, A. Passian, T. Downey, M Buncick, and T. L. Ferrell, Sens. Actuators B, 2000, 69, 51.

28. F. Meriaudeau, A. Wig, A. Passian, and T. L. Ferrell, SPIE, 2000, 4074, 354 .

29. F. Meriaudeau, A. Wig, A. Passian, J. P. Lauret, and T. L. Ferrell, Opt. Eng., 2001, 40, 658.

30. J. C̆tyroký, J. Homola, and M. Skalský, Opt. Quantum Electron., 1997, 29, 301.

31. J. Čtyroký, J. Homola, P. V. Lambeck, S. Musa, H. J. W. M. Hoekstra, R. D. Harris, J. S. Wilkinson, B. Usievich, and N. M. Lyndin, Sens. Actuators B, 1999, 54, 66.

32. D. Liu, Y. Huang, and D. Huang, SPIE, 1999, 3897, 180.

33. Y. Xu, N. B. Jones, J. C. Fothergill, and C. D. Hanning, $J$. Mod. Opt., 2000, 47, 1099.

34. K. Kurihara and K. Suzuki, Anal. Chem., 2002, 74, 696.

35. M. Mitsushio and S. Kamata, Bunseki Kagaku, 1999, 48, 757.

36. M. Mitsushio, T. Yoshidome, and S. Kamata, Bunseki Kagaku, 2000, 49, 307.

37. M. Mitsushio, S. Higashi, and M. Higo, Proceedings of IUPAC International Congress on Analytical Sciences 2001, Anal. Sci., 2001, 17(Supplement), i1721.

38. M. Mitsushio, S. Higashi, and M. Higo, Bunseki Kagaku, 2003, 52, 433.

39. M. Mitsushio, S. Higashi, and M. Higo, Anal. Sci., 2003 , 19, 1421.

40. M. Mitsushio, S. Higashi, and M. Higo, Sens. Actuators A, 2004, 111, 252. 